\title{
The Design and Implementation of an Engineering Education Accreditation Aided Management System
}

\author{
Shengtao Sun, Yuefeng Qi, Peiliang Wu \\ School of Information Science and Engineering \\ Yanshan University \\ Qinhuangdao City, Hebei Province, P.R.China \\ xysst@ysu.edu.cn
}

\begin{abstract}
Engineering Education Accreditation has been widely accepted and recognized by most engineering colleges all over the world based on the idea of Outcome Based Education (OBE). However, current implementation and management methods are of low efficiency and heavy workload. The procedure of engineering education accreditation should not be a temporary or assault work, while it should be periodic and continuous along with regular teaching works. Based on modern information management technology, an assistant information management system is requisite in the procedure of engineering education accreditation. An Engineering Education Accreditation Aided Management System (EEAAMS) has been designed and implemented based on our experience of Engineering Education Accreditation. The paper presents the functional requirement analysis, system architecture construct, operational workflow design and technical implementation plan of this system. And we hope it can play a useful role in the improvement and progress of engineering education.
\end{abstract}

Keywords-engineering education accreditation; outcome based education; process monitoring; quality evaluation; continuous improvement.

\section{INTRODUCTION}

Engineering Education Accreditation [1] is an international quality assurance system of engineering education globally. The world's major industrial countries have established engineering education accreditation mechanisms, and realized the mutual recognition of academic credentials and degrees in global through multilateral agreements [2].

Nowadays, Engineering Education Accreditation has been widely accepted and recognized by most engineering colleges especially famous universities all over the world [3], such as the Massachusetts Institute of Technology and the Stanford University in America, the University of Oxford and the University of Cambridge in England, the Australian National University and the University of Sydney in Australia, and the University of Hong Kong, the Tohoku University, the Nagoya University, the National University of Singapore, and National Taiwan University in Asia, and so on. In early 2016, two majors of Material Molding and Electronic Information Engineering in Yanshan university, as representative of Chinese engineering educations, accepted the investigation and observation of accreditation by the "Washington Accord" (an agreement of international recognition of engineering

This work is funded by the project of Teaching Reform and Practice of Higher Education in Hebei province of China under grant No. 2016GJJG039. programs) [4]. And finally in June 2016, China as an Asia country, was accepted as the Full member of this international organization, which means the global recognition of Chinese engineering educations.

\section{Motivation}

Although most engineering and technology institutes have realized the importance and necessity of engineering education accreditation, there are some limitations of current implementation and management methods, such as low efficiency of operations, mismatch or misunderstanding among staffs, confusion of document and material versions, and so on. Moreover, the procedure of accreditation may add additional burden or workload to the regular teaching process. Take the preparatory procedure for engineering education accreditation of the Electronic Information Engineering major in Yanshan Univeristy as an example, it has cost almost 20 persons about 2 months to write the related reports (about 255 pages and 200 thousand words in total), to catalogue the supporting materials (about 3GB amount of electrical documents), and to collect historical documentations (about 317 copies of appendix files). The procedure of engineering education accreditation should not be a temporary or assault work, while it should be periodic and continuous along with regular teaching works.

The mind and motivation of engineering education accreditation need to be implemented and followed at every stage of engineering education. The accreditation focuses on the assurance mechanism of training targets and a set of normative procedure. Therefore, an assistant information management system is requisite in the procedure of engineering education accreditation. This system contains and performs the process management and quality control architecture based on the standards of engineering education accreditation, which can convert theorization specification and methodology into executable workflow and checkpoints. The goal reaching degree of engineering training can be traced and evaluated in every stage of teaching process, and related records and documents can be stored as electronic files synchronously.

Supported by the Engineering Education Accreditation Aided Management System (abbreviated as EEAAMS) as mentioned above, the data and documents of every checkpoint and stage can be evaluated and recorded. This can help to 
disassemble the centralized mass workload of accreditation preparation to daily slight works along with regular teaching process, which may decrease the influence to regular teaching works and make the accreditation incorporate into daily routines. As far as we know, there are rarely similar research works in domestic engineering colleges. For instance, Xi'an University of Electronic Science and Technology has early point out the feasibility and necessity of this kind of accreditation management system, and Tongji University has designed a Data Collection and Analysis Management System for Engineering Education Accreditation [5], which can analyze variant investigation data and generate report, but lacks the process and document management of accreditation. Moreover, some colleges have developed management information system specific to engineering education [6], but most of them provide information publish and course management based on the methodology of engineering education, without the function of process management or quality assurance. The research proposed in this paper is an exploratory and innovative work, which may promote the standardization and systematization of Chinese Engineering Education Accreditation.

\section{THE DESIGN OF EEAAMS}

The EEAAMS is an assistant system for daily management and monitoring of engineering education accreditation. Based on modern network and information technology, this system can record and trace the whole process and routine works of engineering education, which can help to realize course system improvement, education quality control, and graduate quality evaluation. This section presents some details about the system's functional requirements, technical architecture, and operation specification.

\section{A. Functional Requirements of the System}

The EEAAMS could manage and trace all measurable checkpoints at each stage according to the reference standard and specification of engineering education accreditation. Based on design of self-assessment and evaluation methods, this system could build and check the relevant relations between the training targets of engineering education and graduate requirements, between the graduate requirements and index points, and between the index points and curriculums. The objective achievement scale of each index point could be calculated and analyzed in accordance with the collected data and preserved documents from daily works of engineering education process. And the related data and documents of each index point could be retrieval and obtained as evidences to support the appendix and reference materials in self-evaluation reports of engineering education accreditation.

Moreover, this system could export the tables of basic major state data, the files of teaching management and quality assurance, and relevant evidence materials of each target point as demand. The manager of the system could view and monitor variant operating data of engineering education in time, to find abnormal problems timely and improve the process of engineering education continuously.
As an assistant tool of engineering education accreditation to enhance and normalize the training process, the forecast aim and effectiveness of this system include:

1) The teacher and manager of this system could be assigned certain role with specific job and duty. Each user need to finish his task and submit required documents on the specified checkpoint in time, which can ensure that every job has rules to follow and be more operable.

2) Aided with this system, the complex procedure of engineering education accreditation could be decomposed into daily teaching process, which could relieve the workload of accreditation and improve the efficiency, avoiding unexpected task and interference of regular teaching process.

3) This research work can promote further comprehension and cognition of engineering education accreditation, make its idea and concept throughout the whole teaching process. And the import of modern tools and technology to engineering education accreditation could make it more standardized and refined.

\section{B. Overall Structure of the System}

In the preliminary version of EEAAMS, there are four core functionality modules, namely Training target management module, Curriculum management module, Continuous improvement management module, and Graduate requirements management module separately. The overall system functional diagram is shown in Fig. 1.

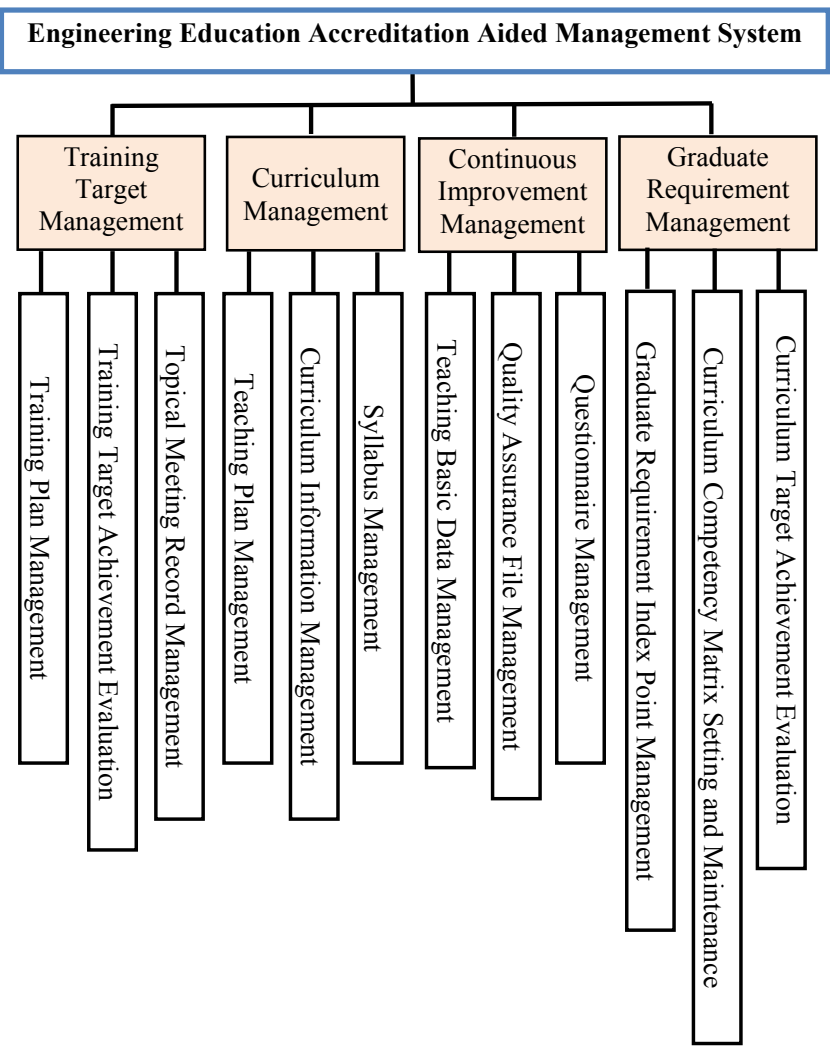

Fig. 1. The System Functional Diagram of EEAAMS 
Aided with this system, the teaching administrative department can monitor the whole teaching process of engineering education and grasp every change or abnormal situation in time, which can help to realize delicacy management. Based on this system, the supervisor of education can evaluate the goal reaching degree of every course and rectify nonstandard problems in time, which can help to make decision on the development and building of the major. Relied on this system, the teachers can conveniently upload and manage related information and files of certain course at each stage of engineering education, which can help to decompose the workload of engineering education accreditation into daily routine tasks. Moreover, all relevant information and documents of engineering education accreditation can be inserted/uploaded and managed in this system, and most part of the self-evaluation report may be generated automatically based on the materials from daily teaching process. The software architecture of this system is shown in Fig. 2.

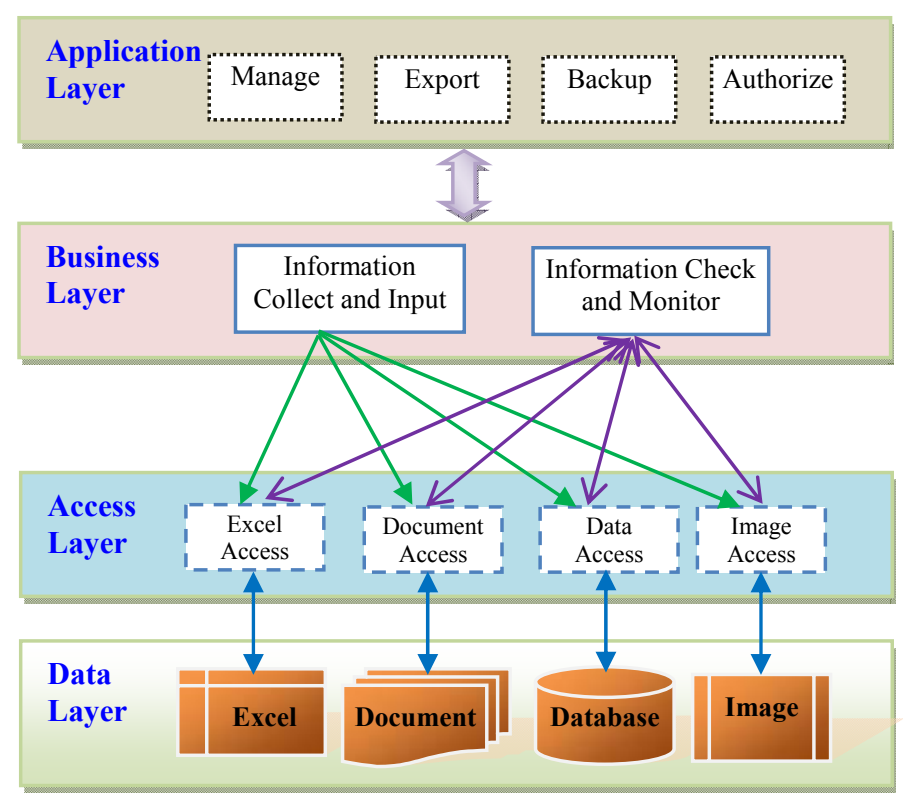

Fig. 2. The Software Architecture of EEAAMS

\section{Operation Specification of the System}

In order to ensure different users could perform their own functions and coordinate between works. The EEAAMS separates users into four roles: system manager, school leader, dean and administrator, and teacher.

The system manager is charge of the basic information maintenance, user and role management, data backup and recovery, system log check, and so on.

The school leader can monitor the whole process, make summary and statistics, export statement and report, and so on.

The dean and administrator are responsible for information and document check, check-point tracing, teaching files upload and management, graduate requirements and index points maintenance, graduate requirement achievement evaluation, and so on.
The teacher of each course is responsible for course files upload, course achievement evaluation and results submission, check results viewing, and so on.

The operation specification and workflow are shown roughly in Fig. 3.

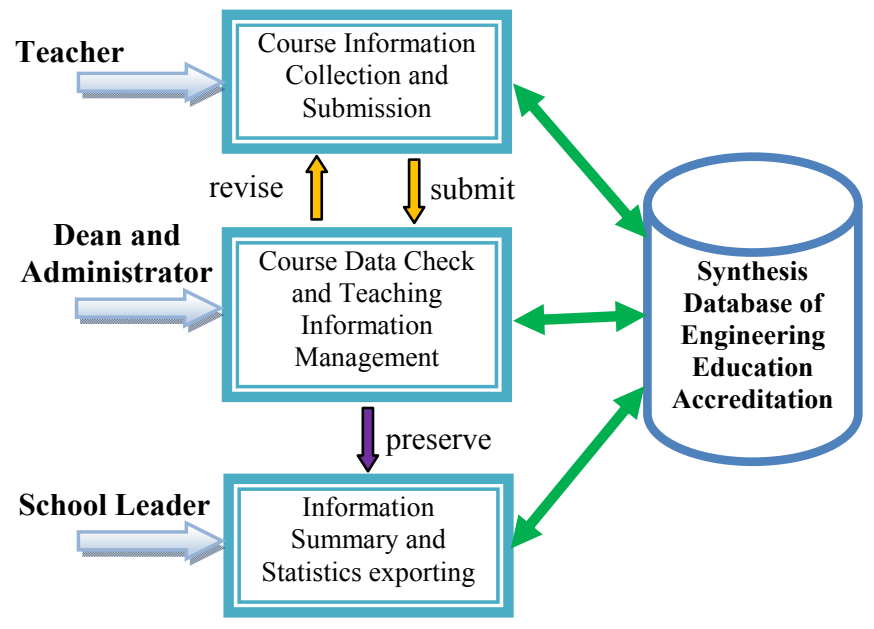

Fig. 3. The operation workflow of system users

The dean and administrator are charge of the checking of course related documents submitted by teachers, such as course syllabus, teaching calendar, teaching outcome evaluation course achievement analysis, and so on. Any doubtful information or nonstandard documents may be returned with feedback to related teacher in time, and the revision need to be submitted and reviewed again. The approval information and documents may be preserved as historical files.

\section{The Plan OF IMPLEMENTATION}

In order to make the EEAAMS more flexible and accessible, this system adopts Browser/Server development mode with JSP (Java Server Pages) Web pages. EasyUI [7] framework will be used in the design and development of user interface, which could avoid the repeated design and coding of cumbersome Javascript and CSS language, and help to improve the efficiency and cost of website construction.

This system will work under the framework of Spring MVC [8]. The Spring Web MVC framework provides ModelView-Controller (MVC) architecture and ready components that can be used to develop flexible and loosely coupled web applications. The MVC pattern results in separating the different aspects of the application (input logic, business logic, and UI logic), while providing a loose coupling between these elements.

1) The Model encapsulates the application data and in general they will consist of Plain Old Java Object.

2) The View is responsible for rendering the model data and in general it generates HTML output that the client's browser can interpret. 
3) The Controller is responsible for processing user requests and building an appropriate model, then passes it to the view for rendering.

The workflow of Spring MVC and the relations among three main elements are shown in Fig. 4.

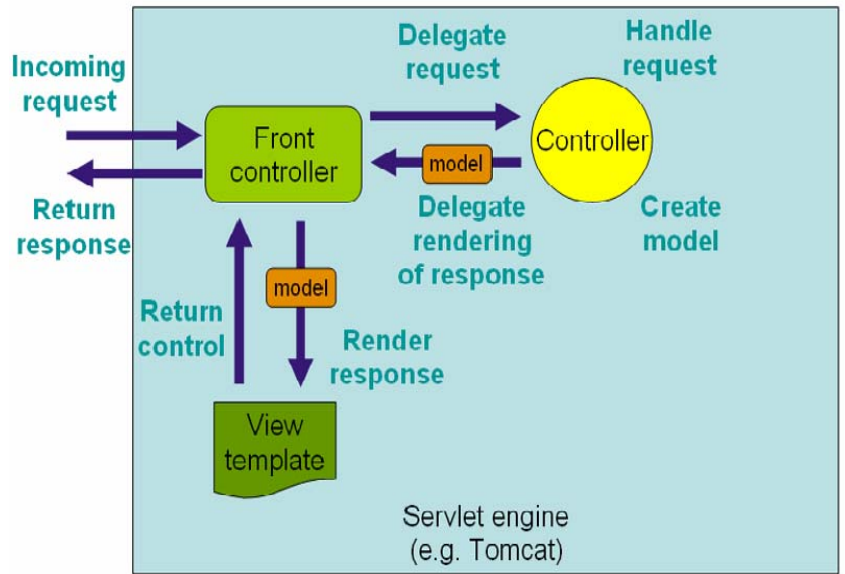

Fig. 4. The Request and Response Workflow in Spring Web MVC

In Spring MVC, the Model-view-controller design pattern helps in separating the business logic, presentation logic and navigation logic. This kind of pattern is very suitable in the application of information management with complex business and has good scalability for future functional upgrade and extension, which could make the EEAAMS flexible with new working procedures and scalable with new functional demands.

\section{CONCLUSION}

The essential purpose of Engineering Education Accreditation is to prompt continuous improvement of current engineering education quality based on the monitoring and evaluation of graduate requirement achievements. The engineering colleges need to train the student under the idea of Outcome Based Education, which can help to cultivate qualified graduates to fulfill the demand of industry development and social progress. With the wide recognition and implementation of Engineering Education Accreditation all over the world, how to implement it more efficiently and assure the effectiveness continuously is an important issue to investigate and research.

In this work, the modern network technology and information management tools are adopted to collect, manage, analyze, evaluate, and preserve all the materials in every stage of Engineering Education timely. Based on the experiences of Engineering Education Accreditation, an Engineering Education Accreditation Aided Management System is proposed and designed. With the assistance of this system, all the information and documents could be collected and preserved along with the process of engineering education, and further monitoring and evaluation of teaching quality could be implemented to find nonstandard problems in time and improve teaching methodology continuously. From the view of teaching staff, everyone has his own duty and specific job involved in the procedure of engineering education accreditation, and every task of engineering education has rules to follow, which is more operable based on this system. The functional requirement analysis, system architecture construct, operational workflow design and technical implementation plan are presented in the paper. However, this work is just a preliminary plan and design of the system, further research works and tasks need to be investigated, such as how to collect and analyze the questionnaire data from graduates efficiently, how to classify and catalogue all the materials with effective index, how to refine and improve the workflow and monitoring method, and so on.

\section{ACKNOWLEDGMENT}

Congratulations on the approval of People Republic of China as the full member of "Washington Accord". This research work is supported by the project of Teaching Reform and Practice of Higher Education in Hebei province of China (No. 2016GJJG039). The authors would like to express great thanks to the supported data from the department of Electronics and Communication Engineering in Yanshan University.

\section{REFERENCES}

[1] A. Patil and G. Condner. Accreditation of engineering education: review, observations and proposal for global accreditation [J]. European Journal of Engineering Education, 2007, 32(6): 639-651.

[2] Accreditation.org. Accrediting Bodies [OL/EB]. http://www.accreditation.org/accrediting-bodies, 2016.

[3] Jiayu Yan. Current status of Engineering and Technology Education [C]. Presidents \& Deans Forum on Engineering Education, Taiwan, China, January 2014. (In Chinese)

[4] Sunyu Wang, Gangcheng Kong, Huan Lei, "Washington Accord" and Significance for Reference towards Higher Engineering Education in China [J]. Research in Higher Education of Engineering, 2007,1:1015.(In Chinese)

[5] Jiaorong Wu, Ying Hui, Xuan Jia, Ye Li. Design and practice of data acquisition and analysis management system for engineering education accreditation $[\mathrm{J}]$. Education Teaching Forum, 2016,29:148-150.(In Chinese)

[6] Chenguang Tang. The resarch and implemetatioin of engineering education practice process management system [D]. Hunan University Master thesis, 2013. (In Chinese)

[7] Ting Luo. Research and Application of EasyUI Asynchronous Tree [J]. Advanced Materials Research,2013,816-817:1116-1120.

[8] Praveen Gupta, M.C. Govil. Spring Web MVC Framework for rapid open source J2EE application development: a case study [J] International Journal of Engineering Science and Technology, 2010, 2(6):1684-1689. 